Proc. Indian Acad. Sci. (Earth Planet. Sci.), Vol. 90, Number 1, March 1981, pp. 47-53. (C) Printed in India.

\title{
Induced magnetic variations at Shillong in relation to regional geology
}

\author{
NANDINI NITYANANDA and D JAYAKUMAR \\ Department of Applied Geology, University of Madras, A.C. College Campus, \\ Madras 600025 , India
}

MS received 11 January 1980; revised 6 June 1980

\begin{abstract}
The Shillong plateau and Mikir Hills form a conspicuous feature in the geologically complex region of Northeastern India. From observations of geomagnetic variations at Shillong a consistent suppression of the vertical $(Z)$ component of variation is noted. From previous analyses of a selected geomagnetic storm observed at Shillong, Ujjain and Jaipur, stations at nearly the same latitude, the complex demodulates of $Z$ variation at Shillong demonstrate this suppression. Results from a comparative study of bays and storm sudden commencements are also cited. An attempt to calculate induction vectors at Shillong was made but they were found to be indeterminate.

However, a case for the presence of induced current concentrations near Shillong is strong, when these characteristics of geomagnetic variations are considered in the context of regional geology. Shillong and the Mikir Hills are the intruded northeastern remnants of the Indian Shield, that have been transported into the Eastern Himalayan syntaxis. But the present data are insufficient to delineate the path of induced currents in the Shillong region or to estimate their intensity.
\end{abstract}

Keywords. Induction ; geomagnetism ; geology ; magnetic variations.

\section{Introdaction}

The Shillong plateau, covering an extent of over $50000 \mathrm{sq} . \mathrm{km}$, is an isolated and conspicuous massif forming the eastern boundary of the Ganga-Brahmaputra plain. The alluvial plain of the Brahmaputra river separates it from the Himalayan ranges to the north. By its position facing the Himalayan range, the Shillong plateau shortens the Himalayan foreland to $35-50 \mathrm{~km}$. Gansser (1964) identified the plateau and Mikir Hills as the northeastern remnant or intrusion of the peninsular shield into the eastern Himalayan syntaxis. The positions of the chief geologic features are indicated in the sketch map in figure 1.

Though it stands physically separate from the Himalayan range, the plateau and its extension, Mikir Hills, reveal a complex character. Consisting of shield rocks, but involved in one of the major tectonic developments of Himalayan orogeny, 


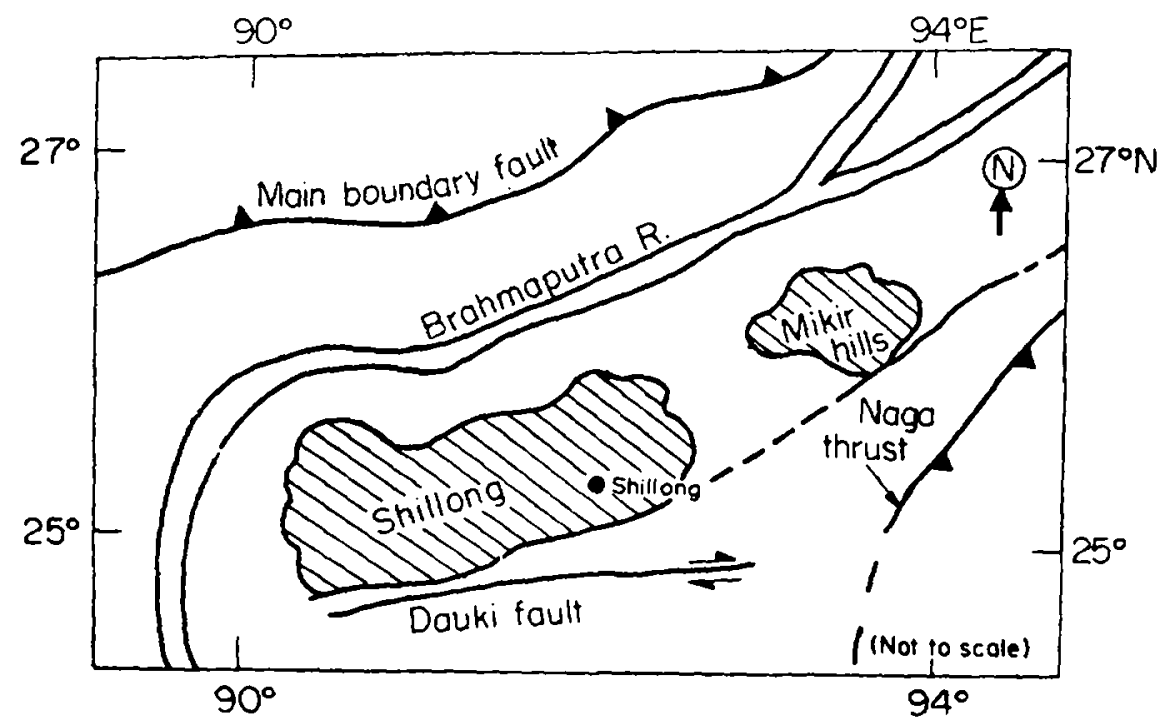

Figure 1. Sketch showing the position of Shillong massif, Mikir Hills and the important geological features in the region.

the Shillong massif must have been subjected to considerable movement. This is a reasonable deduction, considering its position and altered state of the rocks.

The origin of the Naga-Arakan Yoma ranges to the east and south, seismic activity in the region and the resolution of plate boundaries in the Indo-Burmese region are geological and geophysical factors that provide the setting in which interpretation of any geophysical information should be made.

\subsection{Geologic setting of Shillong}

On closer consideration it is seen from various reports on the geology of the Shillong plateau that apart from a geographical proximity to the eastern Himalayan ranges, the plateau is very far removed in geologic history from the ranges. The Shillong plateau and Mikir Hills to the east are unique in that they form the northeasternmost remnants of the peninsular shield elements. These have intruded far into the already complex features of the eastern Himalayan syntaxis. The Shillong massif is only about $50 \mathrm{~km}$ south of the Himalayan foothills and Mikir Hills are flanked on the south-east by the Naga thrust.

The plateau itself has an elevation of upto $1500 \mathrm{~m}$ over the Brahmaputra alluvial plain. Thus it stands out in sharp relief from the surrounding tertiary rocks and alluvial plains. To the south, the plateau has a scarped boundary marking the faulted contact of the shield rocks with surrounding tertiary rocks.

The Archaean rocks of Shillong can be divided into two types: the northern older granites and gneisses, which also outcrop as isolated hills, even north of the Brahmaputra river and the southern Shillong Group that consist of mica, hornbleade and chlorite schists. These are considered to have been metamorphosed from basic rocks. The largest portion of the Shillong outcrop consists of granites 
and gneisses. However, locally enriched sillimanite-cordierite rocks occur, which are said to have been metamorphosed by granite intrusions (Gansser 1964).

The continuation of the Shillong-Mikir Hills massif can be followed to the deeply-faulted basement beneath a thickness of tertiary and quaternary sediments of the Sibsager region, north-east of Mikir Hills. The extension of the faulted southern boundary of the Shillong outcrops therefore appears to be an older fault rejuvenated in the tertiary (Mathur and Kohli 1963). The prominent Dauki fault, striking E-W, lies south of the Shillong plateau, too. Figure 1 is a sketch showing features of geologic interest in the region.

\section{Geomagnetic studies}

A geophysical parameter, that throws light upon the thrusting of continental masses, changes in crustal thickness and lateral changes in temperature is electromagnetic induction. Induced electric currents flowing in the earth upto depths of $400 \mathrm{~km}$ can be detected from the examination of daily records of variations of the geomagnetic field. It was discovered early in these studies that the most striking contrast in electrical conductivity occurring on earth is between land and ocean masses (of the order of $10^{4}$ ). Apart from this there is a global rise in electrical conductivity at the Mohorovicic discontinuity. Several studies have been made on ultrabasic rocks of the upper mantle and lower crust and they have been found similar. The change in conductivity therefore is attributable to phase changes at this depth (Garland 1971).

The analysis of geomagnetic variations to estimate the effect of induced currents comprises various techniques of data processing and criteria for comparison of variations between normal stations (which are considered devoid of the influence of induced currents arising from lateral inhomogeneities), and those stations which exhibit anomalous variations. In this study, the analysis is of two kinds : the qualitative study of discrete geomagnetic events, e.g., bays, storm sudden commencements, etc., which last over a range of periods from $10 \mathrm{~min}$ to $2 \mathrm{hr}$ and time series analysis of periodic phenomena $(10 \mathrm{~min}-200 \mathrm{~min})$ associated with geomagnetic storms.

The magnetic observatory at Shillong was established by the Indian Institute of Geomagnetism in June 1975. The instruments used to record the variations of the components of the geomagnetic field are sensitive suspension variometers (La Cour type) which record the variations photographically. The components, fully describing the geomagnetic field, are horizontal component $(H)$ in the direction of magnetic north, vertical downward component $(Z)$ and declination $(D)$, the angle of deviation of magnetic north from geographic north at that place.

\section{Anomalous variations at Shillong}

The study of a series of magnetic records (magnetograms) from Shillong (Lat. $25^{\circ}$ $34^{\prime} \mathrm{N}$, long. $91^{\circ} 53^{\prime} \mathrm{E}$ ) and a comparison with those from stations at similar latitudes, Ujjain $\left(23^{\circ} 11^{\prime} \mathrm{N}, 75^{\circ} 47^{\prime} \mathrm{E}\right)$ and Jaipur $\left(26^{\circ} 55^{\prime} \mathrm{N}, 75^{\circ} 47 \cdot 5^{\prime} \mathrm{E}\right)$ reveals certain features that are characteristic neither of the events (geomagnetic storms, 
bays, etc.), which are known to be uniform over large regions of the globe, or of the latitudes. Here, the examination of events, occurring in night-time alone, is important because it is known that day-time variations are highly latitudedependent and this is demonstrated very well at the Indian stations, Trivandrum, Kodaikanal and Annamalainagar near the geomagnetic equator (Kane 1978; Trivedi and Rastogi 1968 and other references therein). A comparison of geomagnetic bays is illustrated in figure 2 , where it is seen that $Z$ variations at Shillong are suppressed. This suppression has been noted at all frequencies, however, and another example of it can be seen in figure 3, where the complex demodulates of

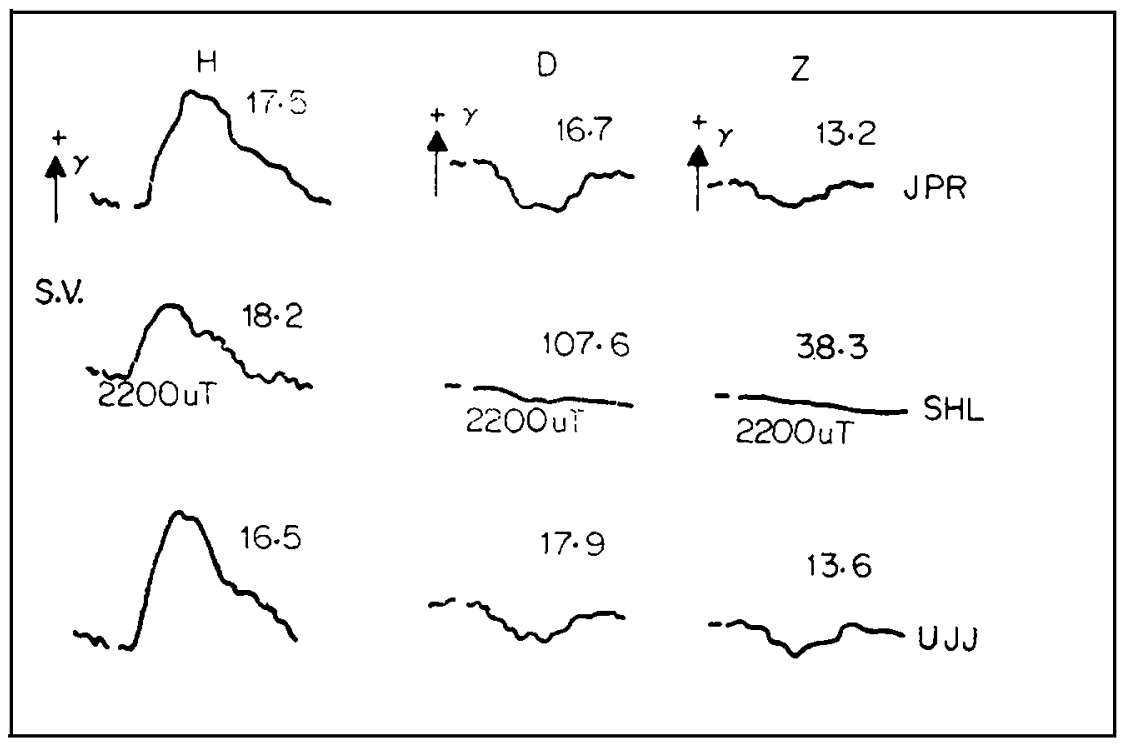

Figure 2. Example of a geomagnetic bay event of 9 March 1976 showing the differences between magnetic variations at Jaipur (JPR), Shillong (SHL) and Ujjain (UJJ). Scale values are in $\gamma / \mathrm{cm}$

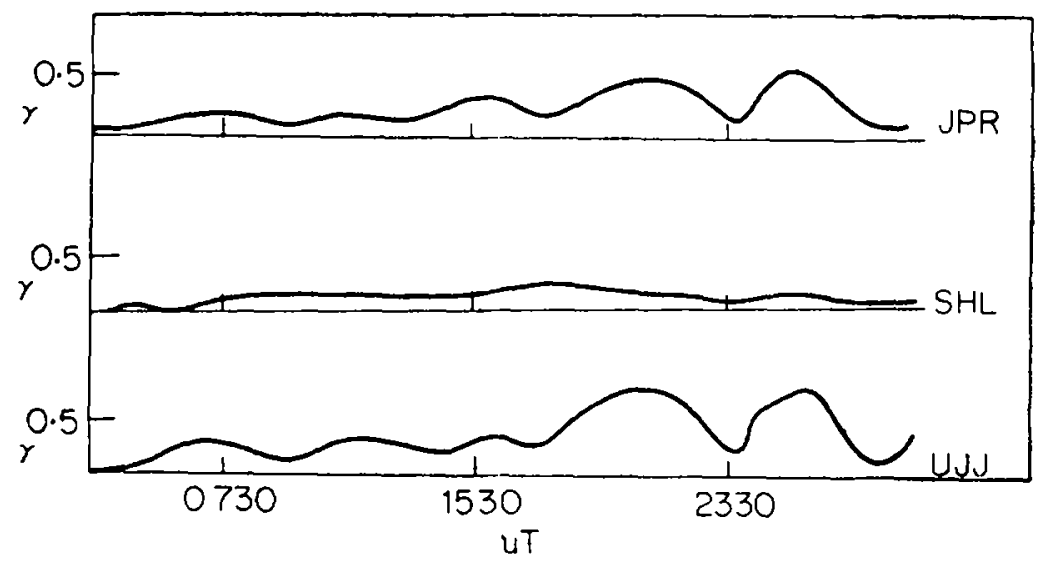

Figure 3. Complex demodulates of $Z$ variations during the magnetic storm of 21 January 1976 of $70 \mathrm{~min}$ period for Jaipur, Ujjain and] Shillong (data from Agarwal et al 1979). 
Table 1. Magnitude and azimuth of induction vectors ( $S$ ) estimated for bays and storm sudden commencements (SSC) at Shillong (Agarwal 1978). Azimuth is full circle bearing, measured from the south.

\begin{tabular}{lcccc}
\hline $\begin{array}{c}\text { Type } \\
\text { of } \\
\text { event }\end{array}$ & $\begin{array}{c}A \text {, Transfer } \\
\text { function } \\
(Z, H)\end{array}$ & $\begin{array}{c}B, \text { Transfer } \\
\text { function } \\
(Z, D)\end{array}$ & $|S|=\left(A^{2}+B^{2}\right)^{\frac{1}{2}}$ & $\begin{array}{c}\text { Azimuth } \\
\theta^{\circ}\end{array}$ \\
\hline Bay & $0.074+0.13$ & $-0.033+0.04$ & 0.08 & $336 \cdot 0^{\circ}$ \\
SSC & $0.21+0.03$ & $0.07+0.12$ & 0.22 & $19 \cdot 3^{\mathrm{c}}$ \\
\hline
\end{tabular}

$Z$ variations during a magnetic storm recorded on 21 January 1976, is shown for all three stations.

The induction vectors, a parameter giving the proportion of $Z$ variations that are induced by the horizontal variations $(H$ and $D$ ) were calculated for 42 bays and 16 SSC (Agarwal 1978) and a degree of correlation between induced $Z$ and inducing $(H$ and $D$ ) variation was found at Ujjain and Jaipur. The magnitude of the vector is small at Shillong and the standard deviation large, consequent to the extremely small amplitudes of $Z$ (table 1 ).

From storm-time variations, the complex demodulates were obtained by a method of fast Fourier transform, filtering for the selected frequency (only 48 and 70 min periods were considered) and inverse fast Fourier transform (Agarwal et al 1979). The result is that the variations, with time, of the selected period alone are obtained, facilitating the study of frequency characteristics in natural phenomena such as geomagnetic storms which usually contain a wide band of frequencies. In the same paper (Agarwal et al 1979), the relative differences in induced variations were studied for ejght stations in India. It was concluded that Sabhawala (lat. $30^{\circ} 22^{\prime} \mathrm{N}$, long. $77^{\circ} 48^{\prime} \mathrm{E}$ ) near Dehra Dun and Shillong exhibited unique variations, each characteristic of anomalous induced currents. The possible reasons for the flow of these currents could not be pinpointed, but it was definitely linked with the tectonics of orogeny which is the dominant factor in any geological or geophysical study in the Himalayas or along the northern edge of the peninsular shield.

\section{Interpretation of geomagnetic studies}

The geomagnetic events studied from records of variation at Shillong reveal a very striking feature: suppression of $Z$ variations at all periods. Unfortunately, the distanco between Shillong and the nearest stations, Jaipur and Ujjain, is very large, thus increasing errors in the estimation of induction vectors and relative enhancement of either of the horizontal components ( $H$ and $D$ ). Therefore, no consistent trend of enhancement or suppression of $H$ or $D$ variations could yet be established. However from the knowledge of the nature of conductivity anomalies and induced current patterns for a probable conductivity configuration, 
i.e. geological structure or abrupt lateral change in medium, the nature of induced variations can be pictured (Lilley 1976). By such means, we can compound a picture of the Shillong plateau which consists of distinct rock types, transported into a region of tectonic complexity. It lies between two major thrusts almost in the bend of the Eastern Himalayan syntaxis. Whatever induced currents flow in this region they will be strongly influenced by the dominant northeast-southwest tectonic trend (see figure 1). Such an induced current pattern will cause maximum suppression of $Z$ variations at Shillong since the station is near the fault trace and not sufficiently displaced to have the usual enhanced $Z$ variations. The relative path of the induced currents, viz., the structures which provide the more conductive channel to the currents, cannot be traced from variations at Shillong alone and, further, the contribution of induced effects to horizontal variations has yet to be estimated. Having a probable model of the conductor required to channel induced currents in this region, we find that this can be given form in the extended fault zone running north-east or eastward from Shillong. If suppression of variations is present at longer periods also the delineation of plate boundaries in the Assam-Burma region would clarify the picture and provide us with further information on probable conductivity contrasts. At present it is considered that consumption of the Burma plate under the Indian one occurs with westward thrusting. The ophiolite belt in the Naga Hills marks the western limit of plate collision here (Dutta and Saikia 1976). The effects on lower crustal and upper mantle rocks, however, may be more widespread than supposed and the intrusion of shield elements to this extent into the syntaxis indicates that the same powerful forces have had their effect in the north, at Shillong and Mikir Hills.

\section{Conclusion}

In the light of recent developments of plate-tectonic studies of the syntaxis and the junction of Indian and Burmese plates related to the orogeny of the region (Naga Hills and Arakan Yoma range) (Dutta and Saikia 1976), the state of the upper mantle and lower crust is yet to be quantitatively investigated. In this context every bit of geophysical information can add to the picture of this complex intracontinental orogeny. Geomagnetic data in the northeastern region of India are sparse. The first continuous records from Shillong show that there is a wealth of detail to be studied. With this single station's records it has been possible to identify the type of induced currents flowing in the region. With additional data from a network of temporary stations in the region and more tectonic information a complex interplay of the geologic structures in the upper crust and the geophysical state of the lower crust and upper mantle can be determined. A magnetometer array experiment in this geologically complex region would be rowarding.

\section{Acknowledgement}

The authors are grateful to Prof. Leelananda Rao, Department of Applied Geology, University of Madras, for his encouragement and to Prof $\mathrm{K}$ Chandrasekharan, 
University of Madras, for his guidance. We thank the Indian Institute of Geomagnetism, for making the data available and Shri A K Agarwal, Indian Institute of Geomagnetism, for sending us his unpublished results.

\section{References}

Agarwal A K 1978 Private communication (unpublished)

Agarwal A K, Singh B P and Nityananda N 1979 Phys. Earth Planet. Inter. 18232

Dutta T K and Saikia M M 1976 Himalayan Geol. 6303

Gansser A 1964 Geology of the Himalayas (ed.) L U de Sitter (London : John Wiley) p. 18

Garland G D 1971 Introduction to geophysics (New York : Saunders) p. 217

Kane R P 1978 J. Geomag. Geoelectr. 30631

Lilley F E M $1976 \mathrm{~J}$. R. Astron. Soc. 46165

Mathur L P and Kohli G 1963 Exploration and development for oil in India, 6th World Petroleum Congress, Sec. 1

Trivedi N B and Rastogi R G 1968 Ann. Geophys. 241037 